DOI 10.36622/VSTU.2020.2.46.006

UDC $625.7 / .8$

M. M. M. Elshamy ${ }^{1}$, A. N. Tiraturyan ${ }^{2}$

\title{
USING APPLICATION OF AN ARTIFICIAL NEURAL NETWORK SYSTEM TO BACKCALCULATE PAVEMENT ELASTIC MODULUS
}

\author{
Al-Azhar University ${ }^{1}$ \\ Nasr City, Cairo, Egypt \\ Don State technical University ${ }^{2}$ \\ Russia, Rostov-on-Don
}

${ }^{1}$ PhD student of the Dept. of Highways, e-mail: mm.elshamy85@gmail.com
${ }^{2}$ PhD in Engineering, Assoc. Prof. of the Dept.of Highways, tel: +7(951)8200303,e-mail: tiraturjan@list.ru

Statement of the problem. The article is devoted to the use of artificial neural networks in solving the problems of processing the results of instrumental recording of bowls of flexible pavement deflections using FWD shock loading settings.

Results. The analysis was carried out, the shortcomings of the existing processing methods were noted, in particular the "backcalculation" method, which consists of a long calculation time, and the instability of the results obtained. The structure of the artificial neural network was built to determine the elastic moduli of the pavement layers. Training of an artificial neural network was carried out using the method of back propagation of error.

Conclusions. The developed neural network has shown good results in training on the test data set, as well as high accuracy of prediction of the elastic moduli of the pavement.

Keywords: pavement, elasticity modulus, artificial neural networks, falling weight deflectometer, backcalculation, deflection bowl.

Introduction. Ensuring the safety of highways is the most urgent task of the road industry of the Russian Federation. Its solution requires a radical revisiting of the existing and longstanding approaches in the field of design, construction and operation of highways including calculation and instrumental foundations. One of the most advanced and promising directions is developing methods for non-destructive testing of the state of non-rigid road pavements, which allows one to solve the issues related to targeted and reasonable assignment of repairs.

(C) Elshamy M. M. M., Tiraturyan A. N., 2020 
Thus, in the practice of road inspection of the Russian Federation, FWD shock loading devices have become common providing the ability to register bowls of elastic deflections and based on them to determine the elastic moduli of structural layers of non-rigid road pavements by means of a procedure called reverse calculation or "backcalculation" [7-14, 19-21].

This procedure involves identifying actual operational values of the elasticity moduli of the structural layers of non-rigid road pavements from the experimental bowl of elastic deflections recorded on site. The reverse calculation mechanism assumes the need to adjust the experimental bowl in relation to the design constructed according to the mathematical model of the pavement for some "initial values of the elastic moduli of the layers", which can be design values of the elastic moduli of the layer materials or the values of the elastic moduli or stiffness moduli established under laboratory conditions. Despite its common use, this method has a number of serious limitations and disadvantages including:

— need to verify the design models according to the data of field tests and testing at proving grounds or by means of accelerated testing facilities;

- complexity of constructing dynamic solutions of the elasticity theory for mathematical models of road pavements;

- complexity of implementation of an effective mechanism for correcting the calculated and experimental bowls of elastic deflections, which makes it possible to provide a high counting rate and a small error between the experimental and calculated values of elastic deflections.

In order to address the issue related to adjustment in the global and domestic practice, multiple methods are being employed such as the gradient descent method, method of successive approximations, etc. However, all of these methods have the above drawbacks. An effective solution seems to be using artificial neural networks (ANNs) which have of late received considerable distribution [15-18]. An artificial neural network is a mathematical model as well as its software or hardware implementation building on the principle of the organization and functioning of biological neural networks, i.e., networks of nerve cells $[1-3]$. Hence the aim of the studies is to develop and train an artificial neural network that allows one to calculate the elastic moduli of the structural layers of non-rigid road pavements according to the bowls of deflections recorded on site. The results of registration of bowls of elastic deflections on the roads of the State Company Russian Highways in the period from 2014 to 2018 have been employed as an experimental foundation for training the artificial neural network. 
1. General provisions of the use of artificial neural networks. The fundamental unit in the design of artificial neural networks is a neuron itself. At the same time, the artificial neural network itself is a collection of neurons linked to each other by connections. A distinctive feature of neural networks is that they are trained for their correct operation. In the process of training, the neural network is able to identify complex dependencies between input and output data as well as to perform generalization. This means that in case of successful training, the network will be able to yield the correct result using the data that was not included in the training sample as well as incomplete and/or "noisy", partially distorted data.

Various versions of the implementation of the structure of artificial neural networks allow you to create self-learning networks that involve multiple exposure to a set of input training data, recognition of their common features and subsequent grouping. Other types of neural networks can be programmed to associate previously specified sets of input patterns with corresponding output patterns.
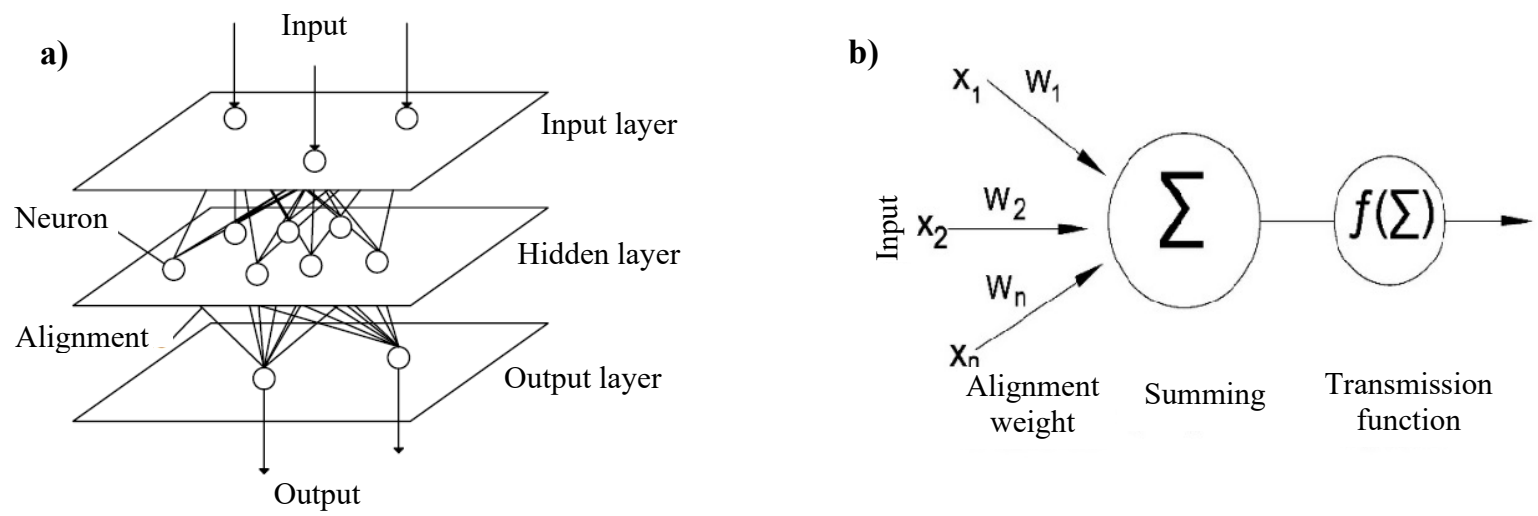

Fig. 1. Structures (a) and algorithm of operation (b) of the artificial neural network

The most widespread neural network architecture is the so-called multi-level feed-forward network. Such networks consist of several neural layers linked by connections with each characterized by a certain weight $\mathrm{w}_{1}, \mathrm{w}_{2}, \ldots, \mathrm{w}_{\mathrm{n}}$.

Hence when the input signal is supplied, information is transmitted from the input layer of neurons via a number of hidden layers to the output layer. As each element passes, a weighted sum is determined (i.e., the sum of the input signals multiplied by their respective scales).

$$
N_{j}=\sum_{i=1}^{n} w_{j i} x_{i}
$$

where $x_{i}$ is a signal passing through into the i-th layer of neurons; $w_{j i}$ is the alignment scales. 
Based on the weighted sum, the activation function is calculated whose value is the output of the neuron. As activation operates, the so-called "single hop" function can be used which assigns a discrete value of 0 or 1 depending on the weighted sum. The issues of neural network training are being given special significance. In supervised learning, a set of training data (pairs of input-output patterns) is provided to the network, one example at a time.

Multi-layer artificial neural networks are trained using a technique known as back propagation of errors [5-6]. Its major point is that the error between the calculated and target patterns of the output data spreads in the opposite direction from the output neural layer via the hidden layers to the input in compliance with the existing connection scales. Then the scales of the connections are changed, which help to reduce the learning error. If training is successful, the link scales reach values that minimize the inference error (commonly expressed as the standard deviation) for all inputs in the training set.

Thus, the error backpropagation algorithm allows distribution of its accumulation between different layers of an artificial neural network and is characterized by a high speed.

\section{Implementation of the reverse calculation of the elasticity moduli of structural layers} of non-rigid road pavement based on an artificial neural network. In this study, a standard non-rigid pavement structure was investigated including a pavement layer, foundation and subgrade soil (Fig. 2a). For each of the pavement layers, the permissible limits of change in their elastic moduli $\left(E_{1}, E_{2}, E_{3}\right)$ were taken. For asphalt concrete layers (E1) these values were $500-4500 \mathrm{MPa}$, for the foundation layer $\left(\mathrm{E}_{2}\right)-80-500 \mathrm{MPa}$, for subgrade soil (E3) 40-150 MPa (Fig. 2).

In order to train the artificial neural network, the values of vertical deflections measured on site, load, pavement temperature and layer thickness were employed. Figure 3 shows a learning algorithm for the artificial neural network. The development of the structure and operation of the artificial neural network was performed in the NeuralNetworks software package. This artificial neural network contains two hidden layers with 20 neurons.

The set of the training data used in this study included the results of calculating the elastic moduli of structural layers of non-rigid road pavements conducted in a specialized software package supplied with an FWD Primax shock loading installation on 581 road sections managed by the State Company Russian Highways. The dataset was split into two blocks. One of them which includes $80 \%$ of all the measurements was used to train the neural network, and the second, which is $20 \%$ of the total, for testing the results obtained using the artificial neural network. 
a)
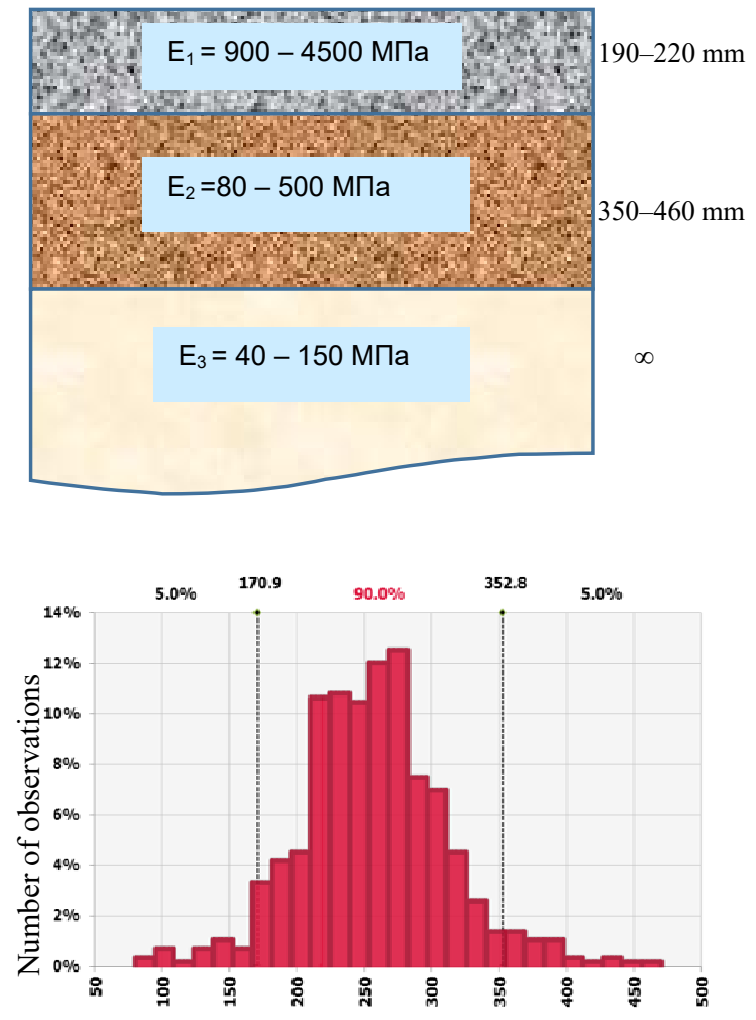

Elasticity modulus of asphalt concrete (E2), MPa

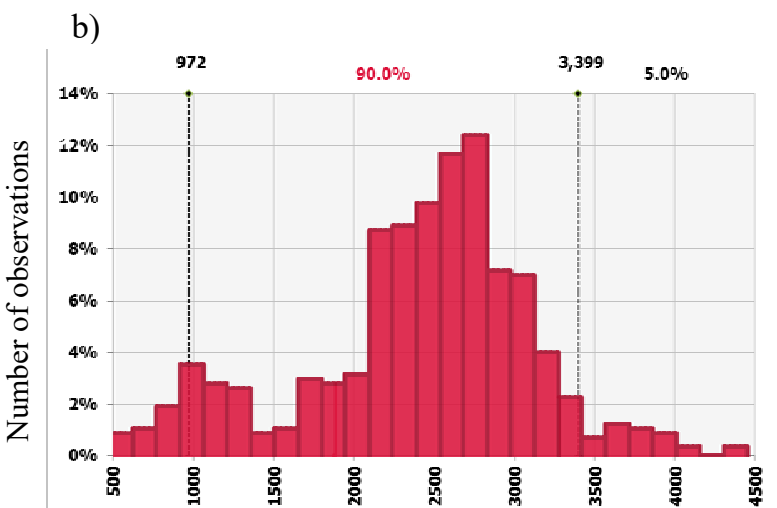

Elasticity modulus of asphalt concrete (E1), MPa

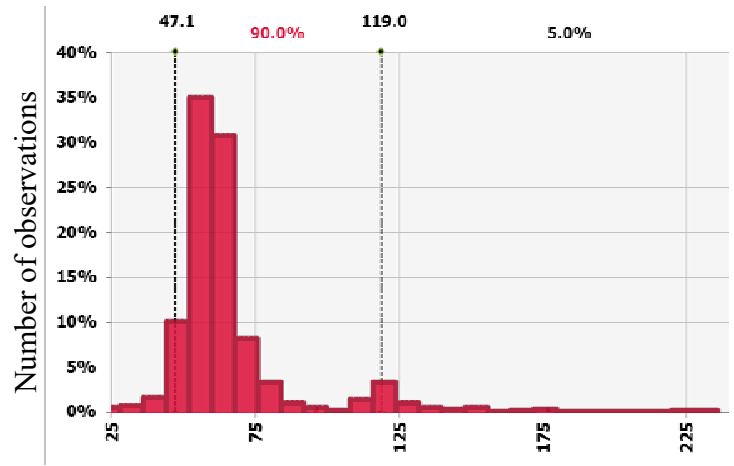

Elasticity modulus of asphalt concrete (E3), $\mathrm{MPa}$

Fig. 2. Input data for training the artificial neural network a) road pavement structure;

b) - d) distributions of the elastic moduli of asphalt concrete layers, foundation, subgrade soil, respectively

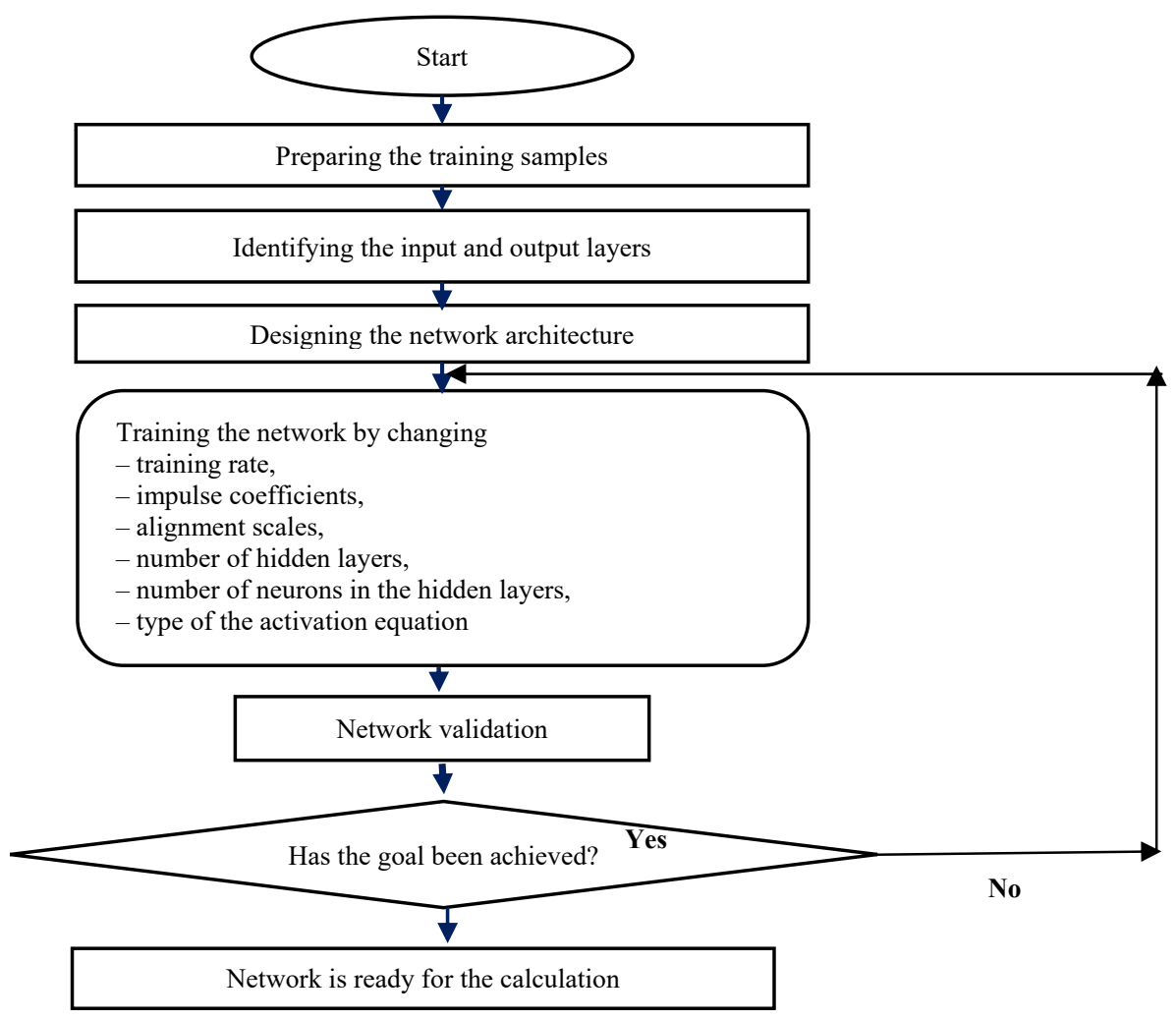

Fig. 3. Designing the artificial neural network 


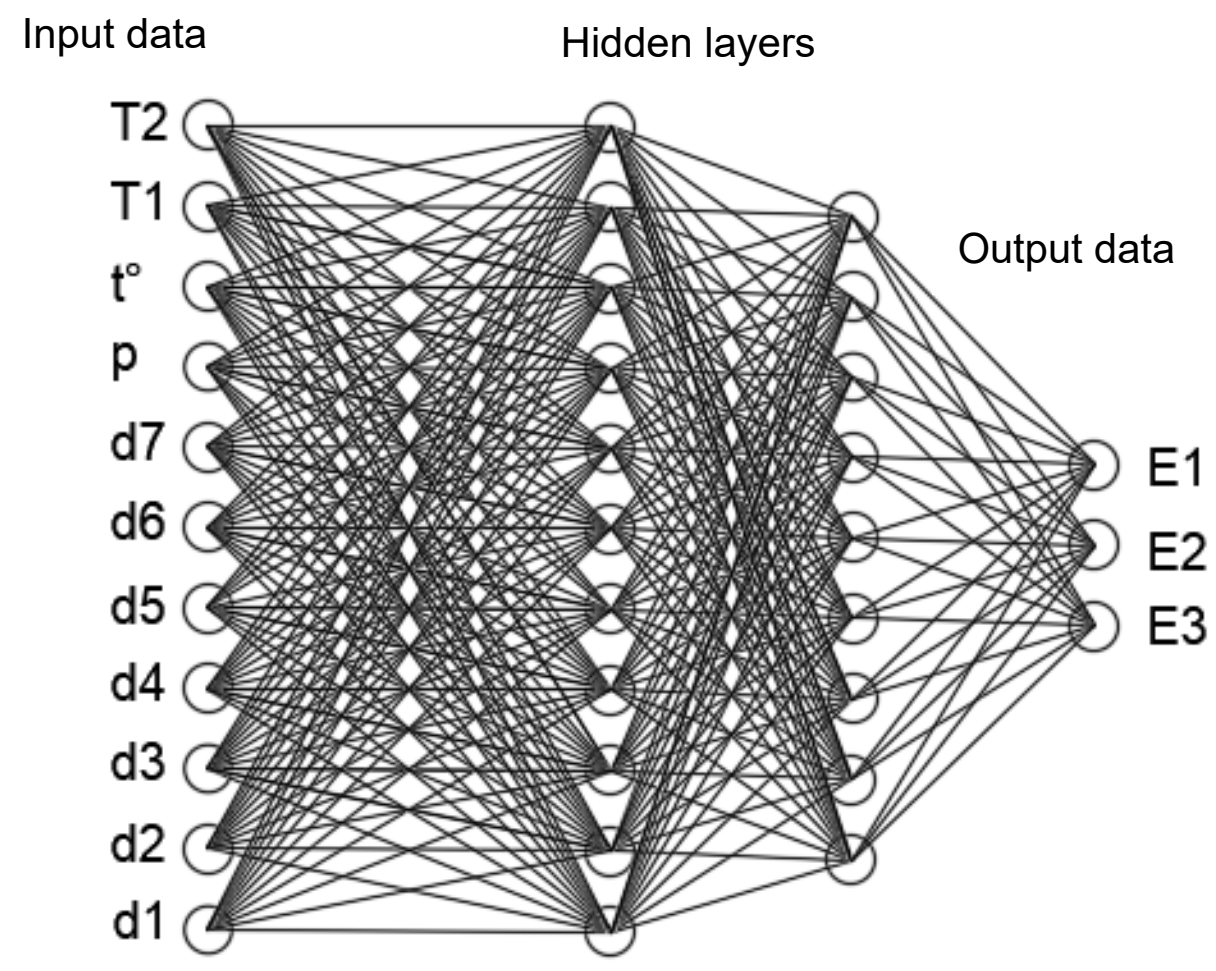

Fig. 4. The structure of the neural network for identifying the elastic moduli of the structural layers of non-rigid road pavements (T1, T2 are the thickness of the layers of asphalt concrete and the foundation of the pavement, $\mathrm{t}^{\mathrm{o}}$ is the temperature on the surface of the pavement, $\mathrm{p}$ is the pressure on the pavement, $\mathrm{d} 1 \ldots \mathrm{d} 7$ are the results of measuring elastic deflections under the sensors-geophones, E1, E2, E3 are the moduli of elasticity of asphalt concrete layers, foundation and subgrade soil, respectively)

Figure 5 shows the results of training the neural network and of test calculations compared with the values of the elastic moduli calculated in the PRIMAX software package. As can be seen from the above graphs, the results of predicting the elastic moduli performed using an artificial neural network are quite similar to the values identified in the specialized software package, which is confirmed by the high values of the coefficients of determination $\left(\mathrm{R}^{2}=0.97-0.99-\right.$ for asphalt concrete layers and the base of the pavement, $\mathrm{R}^{2}=0.95-0.99$ for subgrade soil).

At the same time, use of artificial neural networks for the calculation can considerably increase the speed and stability of the calculation of the operational values of the elastic moduli of the layers of non-rigid road pavements. The speed of calculation using an artificial neural network is 7 times higher than that of correcting bowls of elastic deflections in the Primax software package and more than 15 times of that of the calculation in the AEM software package [4] developed at the RSSU. 


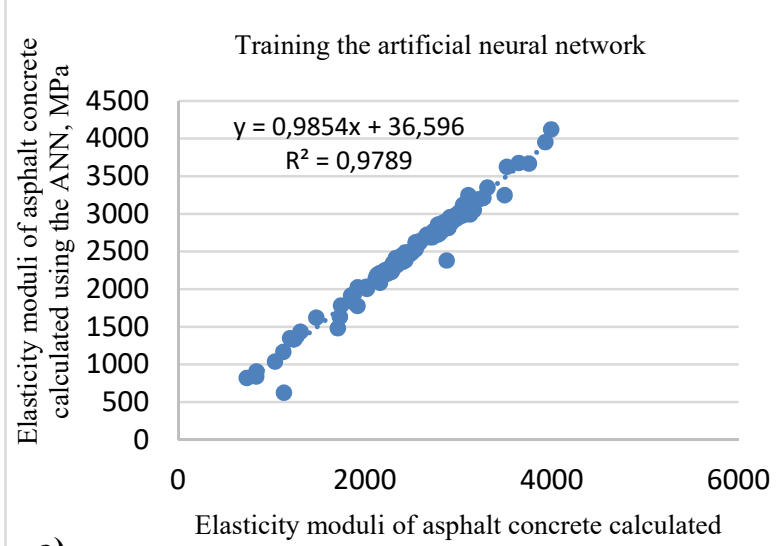

a)

Elasticity moduli of asphalt concrete calculated using the ANN, MPa

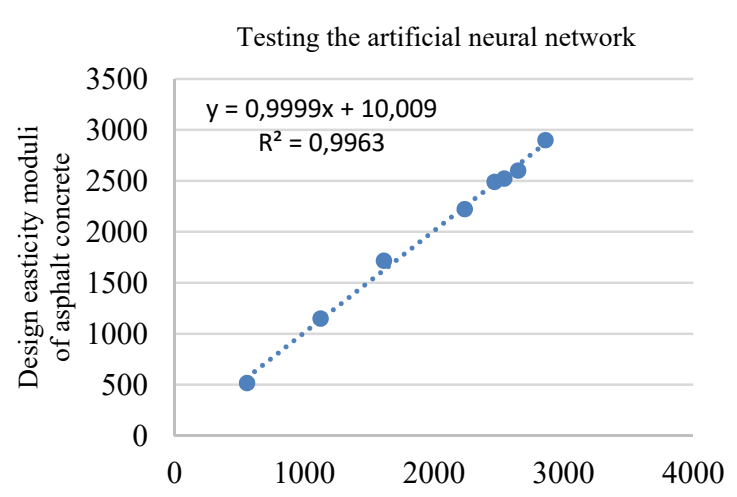

d)

Actual elasticity modulus of asphalt concrete, $\mathrm{MPa}$
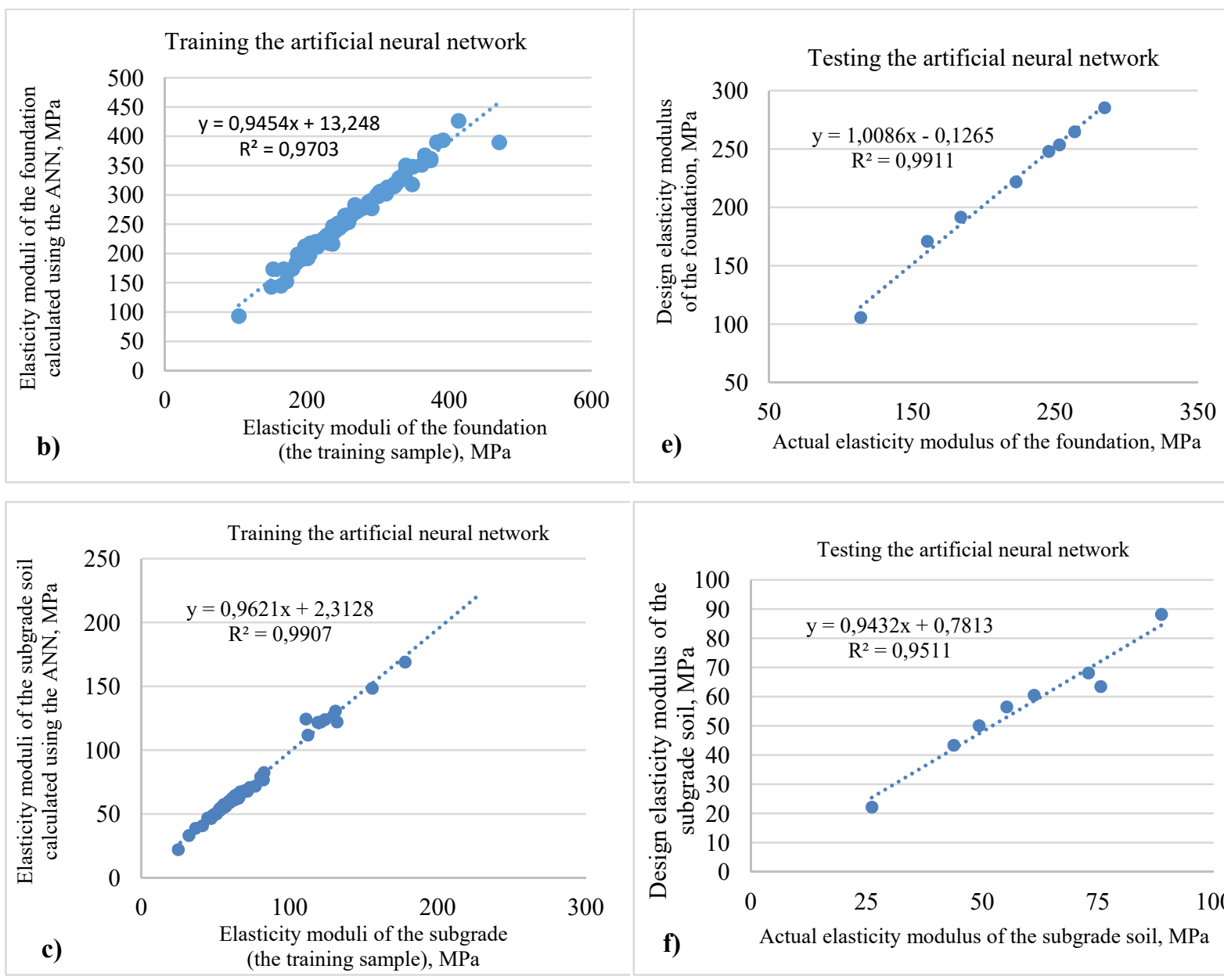

e) Actual elasticity modulus of the foundation, $\mathrm{MPa}$

Fig. 5. Results of training the artificial neural network and identifying the elastic moduli of the pavement layers from the registered bowl of elastic deflections $(\mathrm{a}-\mathrm{c}$ are the results of training the neural network; $\mathrm{d}-\mathrm{f}$ are the results of identifying the elastic moduli of the pavement layers using the artificial neural network and comparing them with the actual values )

The developed artificial neural network was employed as an additional plug-in structural module in the AEM software package. The section of the highway M-1 Belarus, km 
$132+000-160+000$, which is in operation, was taken as a test section for idenitfying the elastic moduli of individual layers of the road pavement. A core drill was used to determine the actual thickness of the pavement structural layers. The pavement layers established using it were $20 \mathrm{~cm}$ for a package of asphalt concrete layers and $40 \mathrm{~cm}$ for a crushed stone base layer by means of the wedge method. The results of identifying the thicknesses of the structural layers of the pavement as well as the bowls of deflections recorded using the FWD PRIMAX 1500 shock loading unit were employed to idenitfy the elastic moduli of the structural layers of non-rigid pavements in this section shown in Table 1.

Table 1

Results of calculating the actual elastic moduli of structural layers of non-rigid pavement on the section of the M-1 highway Belarus, km 160+000-132+000

\begin{tabular}{|c|c|c|c|c|c|}
\hline $\begin{array}{c}\text { Distance, } \\
\mathrm{m}\end{array}$ & $\begin{array}{c}\text { Elasticity modulus } \\
\text { of asphalt concrete }- \\
\mathrm{E} 1, \mathrm{MPa}\end{array}$ & $\begin{array}{c}\text { Elasticity modulus } \\
\text { of the foundation }- \\
\text { E2, MPa }\end{array}$ & $\begin{array}{c}\text { Elasticity modulus of } \\
\text { the subgrade soil }- \\
\text { E3, MPa }\end{array}$ & $\begin{array}{c}\text { Thickness of an } \\
\text { asphalt concrete } \\
\text { layer - H1, mm }\end{array}$ & $\begin{array}{c}\text { Thickness of an } \\
\text { asphalt concrete } \\
\text { layer }-\mathrm{H} 2, \mathrm{~mm}\end{array}$ \\
\hline 0 & 1199 & 223 & 105 & 200 & 400 \\
\hline 3595 & 1722 & 146 & 143 & 200 & 400 \\
\hline 4774 & 1914 & 129 & 108 & 200 & 400 \\
\hline 7386 & 1736 & 104 & 185 & 200 & 400 \\
\hline 7805 & 1556 & 279 & 142 & 200 & 400 \\
\hline 9757 & 1570 & 139 & 102 & 200 & 400 \\
\hline 10638 & 2105 & 344 & 204 & 200 & 400 \\
\hline 11253 & 2248 & 227 & 157 & 200 & 400 \\
\hline 13085 & 1709 & 257 & 81 & 200 & 400 \\
\hline 17318 & 1719 & 285 & 113 & 200 & 400 \\
\hline 18666 & 877 & 123 & 85 & 200 & 400 \\
\hline 21065 & 1283 & 153 & 196 & 200 & 400 \\
\hline 23511 & 2314 & 201 & 135 & 200 & 400 \\
\hline 24856 & 2427 & 141 & & & 4 \\
\hline
\end{tabular}

The analysis of the obtained results shows a decrease in the modulus of elasticity of the package of layers of asphalt concrete relative to the normative values regulated by the current regulatory documents Design Standards for Industrial Roads (ОДН) 218.046-01 "Design of Flexible Road Pavements" and Preliminary National Standards (ПНСТ) 265-2018 "Design of Non-Rigid Pavements". In this case the values of the elasticity moduli of the structural layers of the foundation and the subgrade soil as a whole correspond to the standard values. Indirectly, a decrease in the modulus of elasticity of asphalt concrete layers in this area is confirmed by the results of core sampling of asphalt concrete layers. Thus, e.g., $70 \%$ of the samples ta- 
ken in the lower layer of the pavement and the upper layer of the base made of asphalt concrete in this area have cracks and stratification, which indicates the adequacy of idenitfying the elastic moduli of asphalt concrete layers set up during non-destructive testing using artificial neural network algorithms. The obtained data can be used in the development of projects for repairs and overhauls on operated highways as well as in substantiating a strategy for ensuring the safety of non-rigid road pavements.

\section{Conclusions.}

- A neural network has been developed and trained for identifying the elastic moduli of structural layers of non-rigid road pavements based on the results of instrumental recording of bowls of elastic deflections using a modern FWD shock loading unit, which provides an increased speed and stability of calculations in comparison with traditional software systems supplied with FWD shock loading units.

- The resulting neural network showed excellent results during training on the test dataset (the coefficient of determination was $\mathrm{R}^{2}=0.97$ ) as well as a high accuracy in identifying the elastic moduli of road pavements layers compared with the calculated results of standard software systems (the coefficient of determination was $\mathrm{R}^{2}=0.95$ )

- The results of calculating the elasticity moduli of the structural layers of non-rigid road pavements on the operated section of the M1 "Belarus" highway have been presented. The actual values of the elastic moduli of individual layers of non-rigid road pavements were identified based on the algorithms for processing an artificial neural network which can be employed in the development of projects for small and major repairs of operated highways as well as in substantiating a strategy for ensuring the safety of non-rigid road pavements

- The investigated neural network can be modernized in order to address the problem of identifying the elastic moduli of three or more layered systems while providing a high speed and accuracy, which is critical for processing large data sets on deflection bowls recorded in long sections of highways.

\section{References}

1. Bogoslavskii S. N. Oblast' primeneniya iskusstvennykh neironnykh setei i perspektivy ikh razvitiya [Scope of artificial neural networks and prospects for their development]. Politematicheskii setevoi elektronnyi nauchnyi zhurnal Kubanskogo gosudarstvennogo agrarnogo universiteta, 2007, no. 27, pp. 1-11.

2. Vasenkov D. V. Metody obucheniya iskusstvennykh neironnykh setei [Training methods for artificial neural networks]. Komp'yuternye instrumenty v obrazovanii, 2007, no. 1, pp. 20-29.

3. Voronovskii G. K. Geneticheskie algoritmy, iskusstvennye neironnye seti i problemy virtual'noi real'nosti [Genetic algorithms, artificial neural networks, and virtual reality problems]. Kharkov, Osnowa Publ., 1997. 107 p. 
4. Tiraturyan A. N., Uglova E. V. Programmnyi kompleks dlya «obratnogo» rascheta dinamicheskikh modulei uprugosti ekspluatiruemykh dorozhnykh konstruktsii s uchetom parametrov vozdeistviya ustanovok nagruzheniya dorozhnykh odezhd [Software package for "reverse" calculation of dynamic elastic modulus of road structures in use, taking into account the parameters of the impact of road surface loading installations]. Internetzhurnal Naukovedenie, 2012, no. 3 (12), pp. 143-150.

5. Khaikin S. Neironnye seti: polnyi kurs, 2-e izdanie [Neural networks: a complete course, 2nd edition]. Moscow, Izdatel'skii dom Vil'yams, 2008. 1104 p.

6. Yakh"yaeva G. E. Nechetkie mnozhestva i neironnye seti [Fuzzy sets and neural networks]. Moscow, Binom Publ., 2006. 316 p.

7. Alavi S., LeCates J. F., Tavares M. P. Falling weight deflectometer usage. 2008. NCHRP report, Project no. $20-5,137$ p.

8. Alkasawneh W. M. Backcalculation of pavement moduli using genetic algorithms. Ohio, University of Akron, 2007. 275 p.

9. Öcal A. Backcalculation of pavement layer properties using artificial neural network based gravitational search algorithm. Middle East Technical University, Ankara, 2014. 181 p.

10. Doré G., Zubeck H. K. Cold regions pavement engineering, 2009. 240 p.

11. Harichandran R. S. Modified Newton algorithm for backcalculation of pavement layer properties. Transportation Research Record, 1993, vol. 1384, pp. 15-29.

12. Hassan H. F., Mousa R. M, Gadallah A. A. Comparative analysis of using AASHTO and WESDEF approaches in back-calculation of pavement layer moduli. Journal of transportation engineering, 2003, vol. 129, no. 3, pp. $322-329$.

13. Mahoney J. P. Some observations about backcalculation and use of a stiff layer condition. Transportation Research Record, 1993, no. 1384, pp. 8-14.

14. Saltan M., Terzi S., Küçüksille E. U. Backcalculation of pavement layer moduli and Poisson's ratio using data mining. Expert Systems with Applications, 2011, vol. 38, no. 3, pp. 2600-2608.

15. Elshamy M. Application of Artificial Neural Network System to Predict Pavement Condition Index. Master Dissertation, Al Azhar University, Egypt, 2016. P. 175.

16. Meier R. W., Rix G. J. Backcalculation of flexible pavement moduli using artificial neural networks. Transportation research record, 1994, no. 1448, pp. 75-82.

17. Rohde G. T. MODULUS 4.0: Expansion and validation of the MODULUS backcalculation system. Texas, Texas Transportation Institute, 1990. $128 \mathrm{p}$.

18. Schmalzer P. Long-Term Pavement Performance Program Manual for Falling Weight Deflectometer Measurements, Version 4.1, Report No: FHWA-HRT-06-132 4. 79. Washington, FHWA - 2006. 225 p.

19. Ullidtz P., Stubstad R. N. Analytical-empirical pavement evaluation using the falling weight deflectometer. Transportation Research Record, 1985, vol. 1022, pp. 36- 44.

20. Sharma S., Das A. Backcalculation of pavement layer moduli from falling weight deflectometer data using an artificial neural network. Canadian Journal of Civil Engineering, 2008, vol. 35, no. 1, pp. 57-66.

21. Ceylan H. Backcalculation of full-depth asphalt pavement layer moduli considering nonlinear stressdependent subgrade behavior. International Journal of Pavement Engineering, 2005, vol. 6, no. 3, pp. 171-182. 